\title{
Removal Elemental Mercury from Simulated Syn-Gas over Manganese-based Absorbents
}

\author{
H. W. Cheng, Y. S Lin, and C. T. Yu
}

\begin{abstract}
In this study, a layered carbonate sorbent was prepared by manganese metal and anions with co-precipitation method. There $\mathrm{CO}, \mathrm{CO}_{2}, \mathrm{H}_{2}$, and $\mathrm{CH}_{4}$ gases were mixed within $48.5 p p b$ concentration elemental mercury and used as simulated syn-gas. The mercury removal sorbent was tested in a fixed reactor operation in simulated syn-gas environment. To understand the effects of different temperatures on the removal of elemental mercury, a thermal adsorption test was performed to observe the effect of different temperatures on removal effect. The study found that the Mn-based adsorbent performed best efficiency at $100^{\circ} \mathrm{C}$ and still remained $98.3 \%$ removal rate after continuous eight hours, which was higher than $83.6 \%$ of the adsorption capacity at $25^{\circ} \mathrm{C}$. With the increase of adsorption temperature, mercury removal rate has an increasing trend. However, when the temperature rises above $200^{\circ} \mathrm{C}$, the reducing gas such as $\mathrm{CO}, \mathrm{H}_{2}$ in the simulated gas may react with the manganese metal on the surface of the material to reduce the oxidizing ability of the mercury removal agent for elemental mercury, thereby affecting the mercury removal amount.
\end{abstract}

Index Terms-Elemental mercury removal, syn-gas, Mn-based absorbents.

\section{INTRODUCTION}

Mercury as a major heavy metal contaminant has attracted globally attention and was present in most fossil fuels such as coal naturally. The recent research has found that most of mercury generated from coal combustion remains in flue gas and ash for approximately $39 \%$ and $42 \%$, respectively [1]. The mercury emission from the combustion of fossil fuel is one of the most serious environmental problems and a huge risk to human health because of its bio-accumulation. The U.S. Environmental Protection Agency (EPA) updated the emission limits of mercury and other toxic gas pollution for new power plants under the Mercury and Air Toxics Standards (MATS) on March 28, 2013, and the mercury emission limit for the new power plants and new integrated gasification combined cycle (IGCC) units was $0.003 \mathrm{lb} / \mathrm{MWh}$

[2]. Otherwise, the EU has also made progress to decrease $4.5 \%$ to global mercury emissions to air in 2010 (AMAP/UNEP, 2013) [3]. It can be noted that effective technologies to govern mercury emission from coal-fired power plants require to be developed.

$\mathrm{Hg}$ compounds from coal combustion sources mainly consist of gaseous elemental mercury $\left(\mathrm{Hg}^{0}\right)$, oxidized mercury $\left(\mathrm{Hg}^{2+}\right)$ and particular mercury $\left(\mathrm{Hg}_{\mathrm{p}}\right)$. The methods to remove gas-phase mercury mostly in common are using existing electrostatic precipitator (ESP), wet flue gas

Manuscript received June 1, 2018; revised September 7, 2018.

H. W. Cheng is with the Institute of Nuclear Energy Research, Taiwan (e-mail: hwcheng@iner.gov.tw). desulfurization (WFGD) facilities and activated carbon injection [4]. By way of these removal technologies can effectively remove $\mathrm{Hg}^{2+}$ or $\mathrm{Hg}_{\mathrm{p}}$ in flue gas but ineffective in capturing $\mathrm{Hg}^{0}$ [5]. For this reason in the mercury removal studies, there have been lots of discuss on the elementary mercury removal.

Activated carbon is commercially available for industrial desulfurization, and it has been reported to be effective for removal of $\mathrm{Hg}^{0}$ from flue gas at temperatures below $200{ }^{\circ} \mathrm{C}$. However, the major drawbacks of activated carbons are high costs and narrow operation temperature range [6]. To overcome these shortcomings, it has been reported that activated carbon impregnated with some metal oxides and some novel metal or metal oxides was effective for $\mathrm{Hg}^{0}$ removal [7].

Many precious metal and metal oxides had been used to capture mercury such as $\mathrm{Au}, \mathrm{Ag}, \mathrm{V}_{2} \mathrm{O}_{5}, \mathrm{MnO}_{2}$, etc. They could serve as the oxidant of mercury to oxidize elemental mercury, thereby affecting the mercury removal amount. A comparison of cost and removal capacity of potential sorbents is given in Table I [8].

Therefore manganese oxides as well as ceria have been studied extensively and proven to be good catalysts for $\mathrm{Hg}^{0}$ catalytic oxidation and there are limitations on the use of temperature [9], [10]. A novel material layered double hydroxides (LDHs) are a class of synthetic anionic clays which were containing layer-like structure there some of the divalent cations have been replaced by trivalent ions, giving positively charged plates [11]. The manganese aluminum layered hydrates are often used as adsorbents for heavy metals in wastewater due to their excellent ion exchange properties in the study of pollutants removal [12], but they are rarely mentioned in the removal of mercury. This study will introduce novel layer manganese aluminium mercury sorbent with developed and testing process in a lab-scale fixed-bed system.

\begin{tabular}{lll} 
& \multicolumn{2}{c}{ TABLE I: SORBENT COST } \\
\hline Sorbent & Cost, $\$$ per ton & Capacity $\left(10^{-6} \mathrm{~g} \mathrm{Hg} / \mathrm{g}\right)$ \\
\hline $\mathrm{Au}$ & $10,000,000$ & $1-10$ (on thin films) \\
$\mathrm{Ag}$ & 145,000 & 1 (on thin films) \\
$\mathrm{V}_{2} \mathrm{O}_{5}$ & 12,000 & \\
$\mathrm{PAC}$ & 3,000 & $50-17,000$ \\
$\mathrm{AC}$ & 1,000 & $1-50$ \\
$\mathrm{MnO}_{2}$ & 250 & 200 \\
\hline
\end{tabular}

\section{EXPERIMENTAL}

\section{A. Sorbent Synthesis}

LDH materials are traditionally synthesized by co-precipitation reactions from aqueous solution. The commercial guarantee reagent $\mathrm{Mn}\left(\mathrm{NO}_{3}\right)_{2} * 4 \mathrm{H}_{2} \mathrm{O}$, 
$\mathrm{Al}\left(\mathrm{NO}_{3}\right)_{3} \cdot 9 \mathrm{H}_{2} \mathrm{O}, \mathrm{NaOH}$ and $\mathrm{Na}_{2} \mathrm{CO}_{3}$ was purchased from Merck Chemical Co. LTD. The $\mathrm{Mn}-\mathrm{Al}$ powder was prepared by co-precipitating method with $\mathrm{Mn}\left(\mathrm{NO}_{3}\right)_{2} \cdot 4 \mathrm{H}_{2} \mathrm{O}$ and $\mathrm{Al}\left(\mathrm{NO}_{3}\right)_{3} \cdot 9 \mathrm{H}_{2} \mathrm{O}$ in an alkaline $\mathrm{NaOH} / \mathrm{Na}_{2} \mathrm{CO}_{3}$ solution that contains 0.3 mole $\mathrm{Mn}^{2+}$ and 0.1 mole $\mathrm{Al}^{3+}$ in deionized $\mathrm{H}_{2} \mathrm{O}$ treated with 0.2 mole $\mathrm{NaOH}$ and 0.05 mole $\mathrm{Na}_{2} \mathrm{CO}_{3}$. The mixtures were stirred to mix the acidic solutions with the alkaline solution at constant $\mathrm{pH}$ to form precipitates of $\mathrm{Mn}$ Al for $8 \mathrm{~h}$ after dried and processed through solid-liquid separation. The mixtures were then dried in an oven for $8 \mathrm{~h}$ at $110{ }^{\circ} \mathrm{C}$. The product was denoted as $\mathrm{Mn}-\mathrm{Al}$ layered carbonate.

\section{B. Mercury Removal Test Apparatus}

Mercury removal test apparatus was built specifically for measuring mercury concentration from fix-bed reactor. The testing reactor contains of a $2.5 \mathrm{~cm}$-diameter quartz reactor tube that has a carrier plate of 200 mesh aperture to support powders. A $1 \mathrm{~kW}$ single-stage furnace chamber surrounding the reactor is used to provide the heat. The synthetic flue gas contains gases that mix with $\mathrm{CO}, \mathrm{CO}_{2}, \mathrm{CH}_{4}$ and $\mathrm{H}_{2}$. Mercury was introduced using permeation tubes (VICI Inc., CA) by blending trace amounts of mercury into the synthetic flue gas. $\mathrm{Hg}^{0}$ is immersed in a temperatures-controlled permeation oven and the inlet $\mathrm{Hg}^{0}$ concentration was set at $60 \mathrm{ppb}$ and the total flow rate was controlled at $0.1 \mathrm{~L} / \mathrm{min} .1$ gram of the prepared sorbent was well mixed with $4 \mathrm{~g}$ quartz sand and the bed height of sorbent/sand mixture was about $1 \mathrm{~cm}$. The $\mathrm{Hg}^{0}$ concentration at the outlet of the reactor bed was continuously monitored with an on-line mercury analyzer (EMP-2, Nippon Instrument Corporation, Japan). Fig. 1 shows the schematic of the test apparatus.

With the temperature-controlled mercury removal analysis system at the end of the adsorption fix-bed reactor, the breakthrough curve of mercury removal can be obtained immediately and the residual gas concentration data can be calculated.

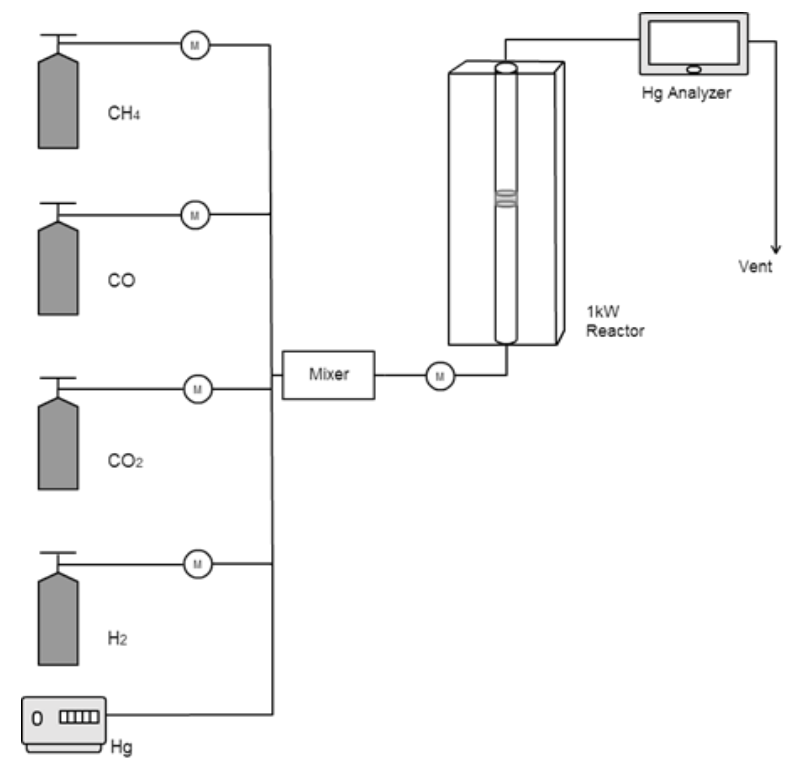

Fig. 1. Schematic of the experimental apparatus.

The mercury concentration and mercury removal ratio were calculated according to the Eq. (1)(2) below:

$$
\mathrm{Hg} \text { capacity }(\mathrm{E})=\left(\mathrm{C}_{0}-\mathrm{Ci}\right) / \mathrm{C}_{0} \times 100 \%
$$

$$
\mathrm{W}_{\mathrm{Hg}}=\int_{0}^{i}(C 0-C i) \times V \times t
$$

\section{Characterization of Sorbents}

The samples were scanned by X-ray powder diffraction (XRD) analysis (D8advance, Bruker, USA) to understand the crystal phase structure. The information of elemental composition of sorbents was measured by XRF spectroscopy (MESA-50, Horiba, Japan) and the surface property was analyzed by scanning electron microscope (SEM, S-4800, Hitachi, Japan). The pore size distribution and Brunauer-Emmett-Teller (BET) surface area were determined using a Micromeritics ASAP $2020 \mathrm{~N}_{2}$ adsorption apparatus.

\section{RESULTS}

\section{A. Characterization of Sorbents}

The XRD pattern is shown in Fig. 2 below. There are both $\mathrm{Mn}_{3} \mathrm{O}_{4}$ and $\mathrm{Mn}_{2} \mathrm{O}_{3}$ were detected on the surface of $\mathrm{Mn}-\mathrm{Al}$ layered carbonate. Fig. 3 shows an SEM image of a $\mathrm{Mn}-\mathrm{Al}$ layered carbonate, which is sticky-like at a magnification of 5000 times. After being magnified to 10,000 times, the agglomerated particle size is approximately $5-10 \mu \mathrm{m}$. The surface area of $\mathrm{Mn}-\mathrm{Al}$ layered carbonate is mesoporous size distribution and pore characteristics are shown in Table II. The crystalline and non-porous characterization of $\mathrm{Mn}-\mathrm{Al}$ is clearly observed as having higher surface areas and pore volumes than $\mathrm{Mn}_{2} \mathrm{O}_{3}$. The concentration of $\mathrm{Mn}, \mathrm{Al}$ was measured by XRF in Table III.

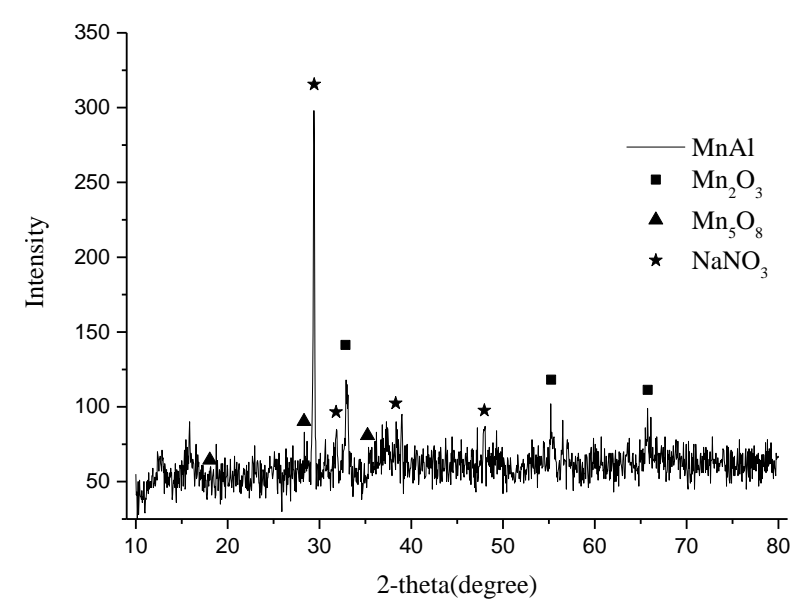

Fig. 2. XRD patterns of the samples.

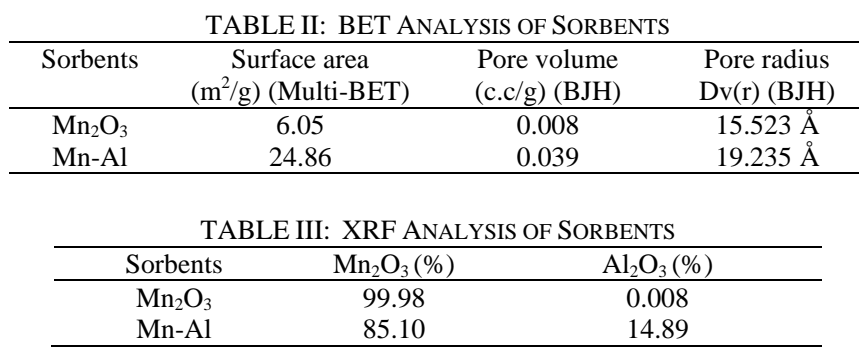

\section{B. Effect of Temperature and Atmosphere on Removal of $\mathrm{Hg}$}

With the temperature-controlled mercury generation source analysis system, the breakthrough curve of mercury removal can be obtained and get the residual gas concentration data immediately. 


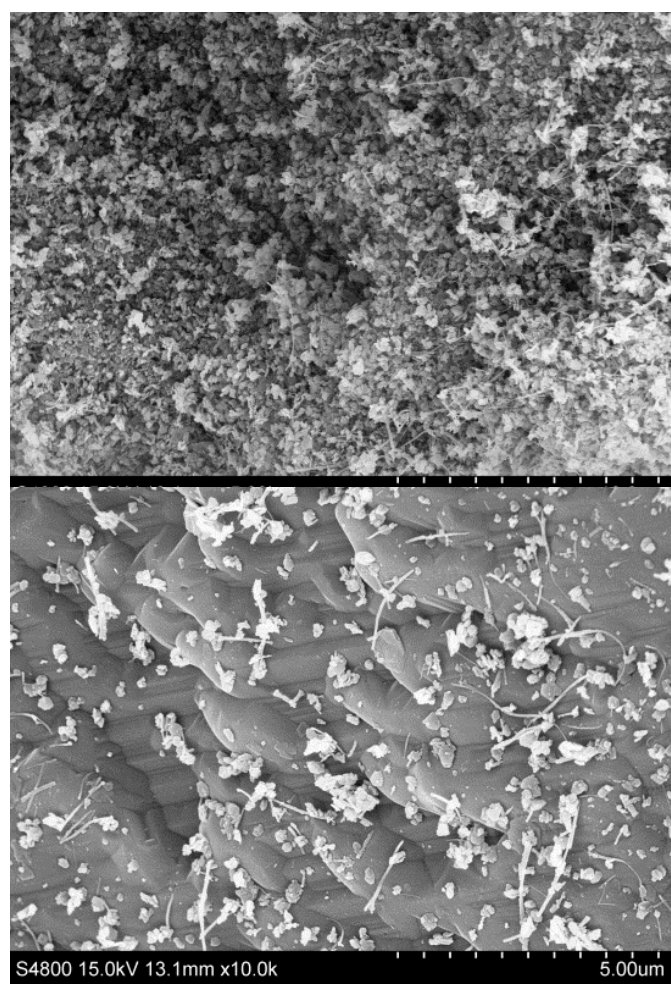

Fig. 3 SEM images of the sorbents.

Equilibrium mercury adsorption equivalent $(\mu \mathrm{g} \mathrm{Hg}$ adsorbed/g adsorbent) were determined by summing the mass of mercury removed from the gas stream based on the acquired breakthrough curves.

As shown in Fig. 4, the results clearly demonstrated that Mn-Al 3:1 was effective than $\mathrm{MnO}$ for elemental mercury removal at $200^{\circ} \mathrm{C}$. The mercury removal rate of $\mathrm{MnO}$ dramatically declined to $50 \%$ comparing with $100 \%$ of $\mathrm{Mn}-\mathrm{Al}$. Furthermore, $\mathrm{Mn}-\mathrm{Al}$ can still maintain a removal rate of more than $90 \%$ after 6 hours continuous experiment.

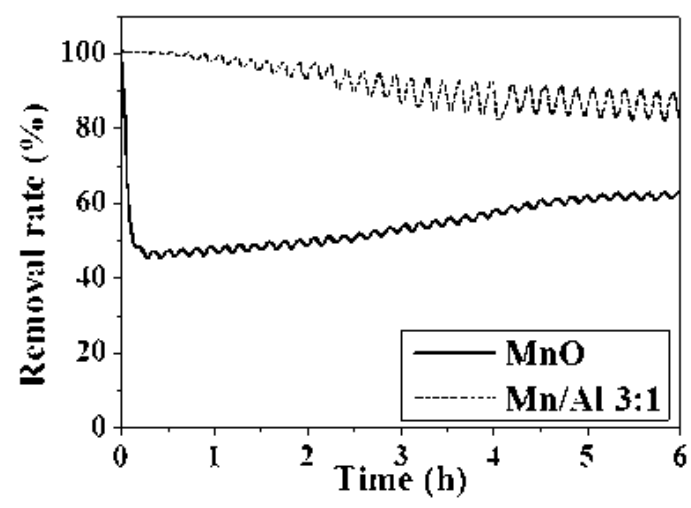

Fig. 4 Mercury adsorption by $\mathrm{MnO}$ and $\mathrm{Mn}-\mathrm{Al}$ at $200^{\circ} \mathrm{C}$.

In Fig. 5, the phenomenon of mercury adsorption equivalent of manganese-based absorbents is reported to increase progressively as the temperature increases from 25 to $300^{\circ} \mathrm{C}$, and decrease at higher temperature. Temperature of adsorption is a critical parameter and has a significant impact on the adsorption of elemental mercury removal efficiency. Manganese-based absorbents showed a best mercury adsorption equivalent $247 \mu \mathrm{g} / \mathrm{g}$ in $300^{\circ} \mathrm{C}$.

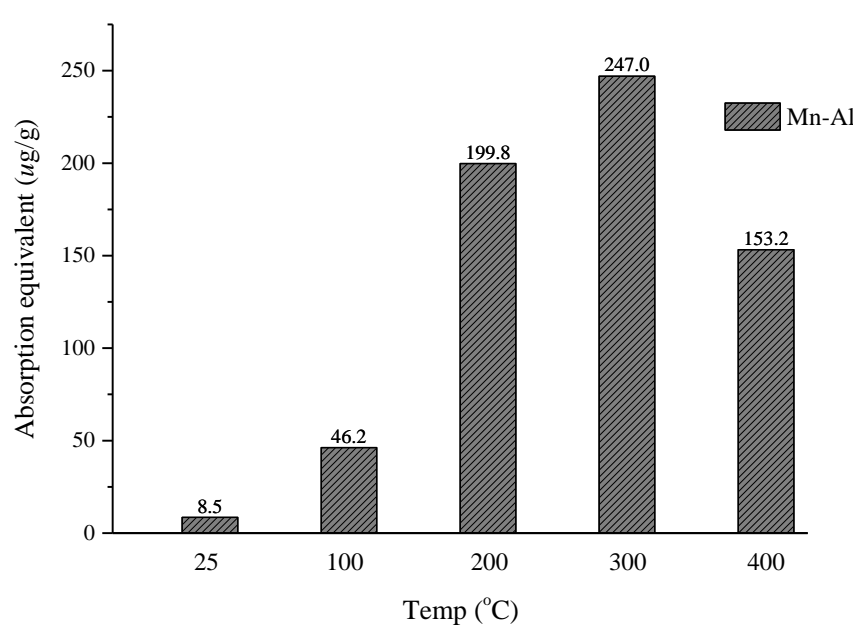

Fig. 5 Mercury adsorption equivalent at $25-400^{\circ} \mathrm{C}$.

The influence of temperature on the adsorption efficiency of the manganese-based absorbents was studied at temperature $25-300^{\circ} \mathrm{C}$ and with flowing $\mathrm{Hg}$ content as $48.5 \mathrm{ppb}$. The testing results of mercury removal on different atmosphere were showed in Fig. 6. When the temperature was increased to 200 and $300^{\circ} \mathrm{C}$, the $\mathrm{Hg}$ removal efficiency remain to nearly $100 \%$ at $\mathrm{N}_{2}$. As shown in Figure 5, with ratio of syn-gas increasing, adsorption capacity of $\mathrm{Mn}-\mathrm{Al}$ absorbent samples decreased dramatically. The capacity of $\mathrm{Mn}-\mathrm{Al}$ absorbent has dropped $53-60 \%$ with ratio of syn-gas increasing from $10 \%$ to $20 \%$ at $300^{\circ} \mathrm{C}$.

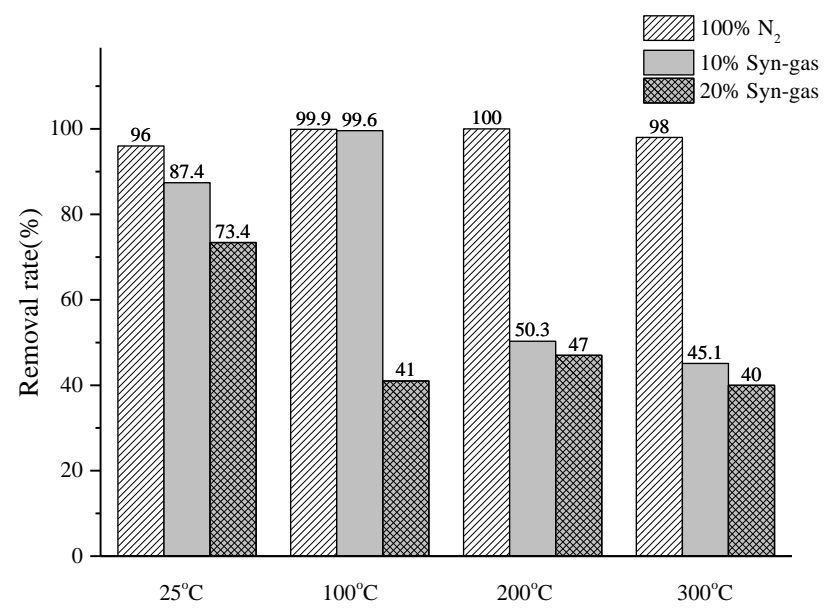

Fig. 6. Mercury removal rate at $25-300^{\circ} \mathrm{C}$ and $0-20 \%$ syn-gas.

\section{CONCLUSIONS}

The study found that the $\mathrm{Mn}-\mathrm{Al}$ absorbent after metal modification performed best at $200^{\circ} \mathrm{C}$ and still had $98.3 \%$ of the adsorption capacity after eight hours, which was higher than $83.6 \%$ of the adsorption capacity at $25^{\circ} \mathrm{C}$. With the increase of adsorption temperature, mercury removal rate has an increasing trend. However, when the temperature rises above $200^{\circ} \mathrm{C}$, the reducing gas such as $\mathrm{CO}, \mathrm{H}_{2}$ in the simulated gas may react with the manganese metal on the surface of the material to reduce the oxidizing ability of the mercury removal agent for elemental mercury, thereby affecting the mercury removal amount.

Compared with precious metal absorbents, the $\mathrm{Mn}-\mathrm{Al}$ absorbent can reduce the cost of synthesis and achieve the 
purpose of improving the working temperature and the removal efficiency. This research may contribute immediate use for mercury removal in coal and cement industry to meet mercury regulations.

\section{ACKNOWLEDGEMENTS}

The authors wish to acknowledge the contribution of the financial support of National Science Council of the Republic of China, Taiwan under Contract No. MOST 107-3113-E-008-002.

\section{REFERENCES}

[1] S. Strite and H. Morkoc, "Global circulation of atmospheric mercury: a modeling study," Atmos Environ, vol. 38, pp. 147-161, 2004.

[2] U. S. EPA, "Updated emission limits for new power plants under the Mercury and Air Toxics Standards (MATS)," April 24, 2013.

[3] European Environment Agency, "European Union emission inventory report 1990-2015 under the UNECE Convention on Long-range Transboundary Air Pollution (LRTAP)," 2017

[4] N. Miyata, S. Kido, P. Honeycutt, and D. Harris, The Proceedings of Mega Symposium, Chicago, Illinois, USA2001

[5] J. C. S. Chang, "Simulation and evaluation of elemental mercury concentration increase in flue gas across a wet scrubbe," Environ. Sci. Technol, vol. 37, pp. 5763-5766, 2003.

[6] S. Krishnan, B. K. Bullett, and W. Jozewicz, "Sorption of elemental mercury by activated carbon," Environ. Sci. Technol, vol. 28, p. 1506 , 1994.
[7] J. Granite, R. Myers, P. King, C. Stanko, and W. Pennline, "Sorbents for mercury capture from fuel gas with application to gasification systems," Industrial and Engineering Chemistry Research, vol. 45, no. 13, pp. 4844-4848, 2006.

[8] E. J. Granite, H. W. Pennline, and R. A. Hargis, Sorbents for Mercury Removal from Flue Gas, 1998

[9] L. Yangxian and Y. G Adewuyi, "A review on removal of elemental mercury from flue gas using advanced oxidation process: Chemistry and process," Chemical Engineering Research and Design, vol. 112, pp. 199-250, 2016.

[10] S. Cimino and F. Scala, "Removal of elemental mercury by $\mathrm{MnO}_{x}$ catalysts supported on $\mathrm{TiO}_{2}$ or $\mathrm{Al}_{2} \mathrm{O}_{3}$," Ind Eng Chem Res, 2015.

[11] K. Aamir and O. Dermot "Intercalation chemistry of layered double hydroxides: recent developments and applications," J. Mater. Chem, issue 11,2002

[12] K. Reddy, J. He, W. Thiel, G. Pinto, and G. Smirniotis, "Sulfur-tolerant $\mathrm{Mn}-\mathrm{Ce}-\mathrm{Ti}$ sorbents for elemental mercury removal from flue gas: Mechanistic investigation by XPS J," Phys Chem C, vol. 119, no. 16, pp. 8634-8644, 2015.

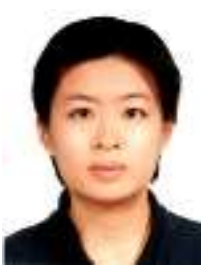

Han-Wen Cheng is a staff researcher at the Institute of Nuclear Energy Research. Her research interests include the environmental sciences and removal of hazardous waste. 